\title{
A COMUNICAÇÃO POLÍTICA NO CENÁRIO DEMOCRÁTICO CONTEMPORÂNEO: UM ESTUDO COMPARATIVO DA ESTRUTURA ELEITORAL BRASILEIRA E NORTE-AMERICANA
}

\author{
COMMUNICATION POLICY IN CONTEMPORARY DEMOCRATIC \\ SCENARIO: A COMPARATIVE STUDY OF BRAZILIAN ELECTORAL \\ STRUCTURE AND AMERICAN
}

POLÍTICA DE COMUNICACIÓN EN ESCENARIO DEMOCRÁTICO CONTEMPORÁNEO: UN ESTUDIO COMPARATIVO DE ESTRUCTURA ELECTORAL DE BRASIL Y EE.UU

\author{
Roberto Gondo Macedo \\ Dr, UPM \\ r.gondomacedo@gmail.com \\ Paulo Cezar Rosa \\ Dr, UMESP \\ paulocezarrosa@uol.com.br
}

\begin{abstract}
Resumo
O profissionalismo dos atores envolvidos no ambiente político é notório tanto no cenário norte-americano como no brasileiro. As ações e planejamentos de comunicação política envolvem diversas áreas do conhecimento e se tornam mais estratégicas a cada pleito eleitoral. É objetivo do artigo a apresentação de um estudo comparativo das estruturas eleitorais dos dois países, com foco nas articulações das campanhas, na visão da comunicação política eleitoral e pós-eleitoral. Apresenta um panorama das Associações que promovem a profissionalização dos Consultores Políticos, tanto no âmbito do pragmatismo mercadológico, como também no universo de pesquisas no ambiente acadêmico. Análises comparativas binacionais são necessárias na égide da comunicação política, visando demonstrar os mais diversos comportamentos eleitorais.
\end{abstract}

Palavras-chave: Comunicação política; estratégias eleitorais; eleições.

\begin{abstract}
The professionalism of the actors involved in the political scenario is noticeable in both the U.S. and in Brazil. The actions and plans of political communication involve many areas of knowledge and become more strategic to each election. Aim of the paper is to present a comparative study of electoral structures of the two countries, focusing on joint campaigns, in the view of political communication election and post-election. Presents an overview of Associations that promote the professionalization of Political Consultants, both within the marketing pragmatism, but also in the world of research in an academic setting. Comparative analyzes are necessary in binational aegis of political communication in order to demonstrate the various behaviors election.
\end{abstract}

Key words: Political communication, electoral strategies; elections. 


\section{Resumen}

La profesionalidad de los actores involucrados en el escenario político se nota tanto en los EE.UU. y en Brasil. Las acciones y planes de comunicación política implica muchas áreas del conocimiento y llegar a ser más estratégico para cada elección. Objetivo de este trabajo es presentar un estudio comparativo de las estructuras electorales de los dos países, centrándose en campañas conjuntas, a juicio de la comunicación política electoral y postelectoral. Presenta una visión general de las Asociaciones que promueven la profesionalización de Consultores Políticos, tanto en el pragmatismo de marketing, sino también en el mundo de la investigación en un ambiente académico. Análisis comparativos binacionales son necesarios en la comunicación política con el fin de demostrar las elecciones de comportamientos diversos.

Palabras clave: Comunicación politica, estrategias electorales, elecciones

Esta obra está licenciada sob uma Licença Creative Commons

\section{INTRODUÇÃO}

Um cenário democrático não é igualitário, pelo menos quando se refere à competitividade acirrada das agremiações partidárias e políticos para a conquista de pleitos eleitorais e o sucesso de aprovação nas respectivas gestões públicas. O convívio em um ambiente de liberdade de expressão e acessibilidade ao capital promove uma busca pela excelência nas ações presentes em todos os segmentos da sociedade.

$\mathrm{Na}$ área da comunicação política os planejamentos de campanhas eleitorais e construção de imagens públicas vitoriosas são mais complexos e exigem integrações interdisciplinares para a execução de pressupostos de controle e gerenciamento.

Para Araújo (2008, p.28) "se na democracia a comunicação é decisiva para o poder político, ela inevitavelmente fará da comunicação não apenas um problema de informar e ligar, mas uma questão de fazer".

A realidade brasileira com a conquista democrática não aconteceu no mesmo período que os norte-americanos, apesar do período de independência colonial ocorrer ao final do século XIX, vários problemas nos períodos republicanos inibiram um fortalecimento do espírito democrático unido com maturidade na tomada de decisões sociais.

O cenário atual somente foi conquistado com a redemocratização brasileira, até esse momento, as ações de comunicação relacionadas à política e poder público não eram explícitas e permitidas para a sociedade, ficando direcionadas apenas a conotações de propagandas ideológicas e governamentais da gestão ditatorial do regime militar. 
O processo eleitoral norte-americano influenciou muitas ações na forma de conduzir e abordar a população diante de competitividades eleitorais. Apesar de multipartidário, a décadas existe uma polarização em dois macros blocos: Republicanos e Democratas, as estratégias adotadas para a construção de imagem e aproximação com a real necessidade da população estão próximas ao estilo latino, mais precisamente brasileiro.

Apesar de o Brasil ser pluripartidário, as ações de análise comportamental de grande parte dos brasileiros são próximas das promovidas nos EUA, vista a adequação de um novo cenário constituído nas últimas quatro décadas, onde as comunidades afrodescendentes e latinas influenciam na ordem de escolha das prioridades nacionais.

Os avanços tecnológicos da informática e dos canais de comunicação interativos já se fazem presentes nos dois países. A influência da web nas eleições norte-americanas é muito acentuada nos dias atuais, tanto para propaganda política, como para captação de recursos para campanha, nesse sentido, pelo viés cultural e problemas de acessibilidade por grande parte da população brasileira, o universo eletrônico para a política ainda é restrito e em evolução tardia.

Na última campanha presidencial dos Estados Unidos

o uso da internet foi bastante importante, em particular mediante banners em sites de grande acesso, tanto para atingir os adversários como para levantar recursos[...] os banners que apresentaram melhores resultados foram aqueles colocados em sites de informação que os usuários procuram com maior disponibilidade de tempo (esportes, clima). Os especialistas em marketing político ainda não descobriram todo o potencial da internet nem perceberam a necessidade de rever o uso das mídias tradicionais em razão do impacto da rede mundial. (SORJ, 2010)

O Brasil convive com um acentuado problema de inclusão digital, principalmente nas regiões Norte, Nordeste e Centro-Oeste do país. A ausência de políticas públicas eficazes para o combate a má qualidade da educação e acessibilidade da informação para a real gestão do conhecimento inibe maior participação da população dos debates políticos em ambiente eletrônico, em muitos dos casos, do presencial também, decorrente da falta de arcabouço analítico e informacional.

O acesso às TICs não é suficiente se não está acompanhado de "apropriação" da ferramenta - processo do qual é chamada "alfabetização digital" faz parte, com o uso relacionado à melhoria das condições de vida do usuário e a conseqüente geração do conhecimento que se transfere, entre outros fatores possíveis, à geração de conteúdo. (ALVA DE LA SELVA, 2006, p. 6).

Em contrapartida o sistema eleitoral de votação brasileiro com a estrutura da Urna Eletrônica, implantado de modo de amostragem no ano de 1996 é atualmente modelo de 
logística organizacional e informacional para muitos países democráticos, visto a rapidez na condução dos pleitos eleitorais e condução com alta velocidade na apuração de votos.

\section{DESENVOLVIMENTO}

\subsection{Ações de comunicação política no universo democrático}

A comunicação política é um segmento comunicacional recente no sentido organizacional e de planejamento no Brasil. Ações relacionadas à comunicação de atores políticos sempre estivem presentes na história nacional e de qualquer país do globo, essa premissa se sustenta partindo do princípio da necessidade de construção de imagem de uma pessoa pública, nesse caso, envolvida no cenário político social.

A expressão comunicação política (CP) vem sendo usada com múltiplos
significados, frequentemente conflitantes, dependendo do país, do autor e do
contexto em que é utilizada. Tamanha diversidade demonstra que a
expressão ainda não é um conceito claro, nem mesmo uma área de atuação
profissional delimitada. Pelo menos por enquanto, Comunicação Pública é
uma área que abarca uma grande variedade de saberes e atividades e pode-se
dizer que é um conceito em processo de construção. (BRANDÃO, 2007,
p.1).

As ações de comunicação no poder público podem ser relacionadas como impérios, governos democráticos republicanos e ditatoriais, pois, a essência do processo de comunicação e construção de uma imagem pública sustentável perdura por todos esses cenários.

No Brasil, o governante que mais fez uso das condições de comunicação política foi Getúlio Vargas nos seus dois períodos no comando da nação: na primeira fase, pelo regime do Estado Novo (1930-1945), conquistado por intermédio de um golpe de estado com apoio dos militares e o segundo período (1951-1954), já com eleições diretas para presidente da república.

Com a inteligência estratégica de seu assessor Lourival Fontes, foi criado o DIP Departamento de Imprensa e Propaganda que fiscalizava todos os canais de comunicação brasileiros com objetivo de fortalecer o controle da informação para a população. Fez uso intenso do rádio, até então um dos poucos recursos que chegavam à maioria da população brasileira, com a criação do programa "Hora do Brasil".

Segundo Haswari (2008, p.38) "com esse modelo, consolidava-se no Brasil o mecanismo de Benito Mussolini, de falar sozinho para ninguém contestar, o espetáculo do 
poder tinha intuitos bastante claros: a criação do mito, o controle rigoroso da força política emergente, a exclusão do intermediário e a implantação do populismo".

Nesse período, a comunicação estatal fomentava na população o conceito do patriotismo e nacionalização, que permitia o uso dessa retórica nas comunicações dos postulantes a cargos eletivos, pois já se instituía a conotação da participação política brasileira e crença no crescimento econômico brasileiro.

O período compreendido entre 1964 a 1978 ficou caracterizado pela intervenção dos militares no sistema político brasileiro. A comunicação política também foi utilizada nesse período, buscando desenvolver um clima de credibilidade na sociedade com os militares no processo decisório no país.

A grande atuação de comunicação dos militares nesse período foi o acentuado foco de patriotismo presentes nas peças publicitárias dos projetos desenvolvidos e nas divulgações das ações governamentais. No final da década de 70, com o desgaste natural do sistema ditatorial, o movimento promovido pelos atores sociais, instituído como "Diretas Já", com vistas ao direito do voto direto para as instâncias políticas nacionais ganhou força e comoção da população em grande parte dos estados da federação.

Com a redemocratização brasileira, a profissionalização das ações de comunicação política ganha força, com associações, participação e formação por instituições de ensino permitindo a melhoria na qualidade dos envolvidos no processo estratégico de comunicação no ambiente público.

Diante desse arcabouço de fundamentação, é possível afirmar que, independente do período e do sistema de governo vigente em um país é necessário o desenvolvimento de estratégias de comunicação com a população, visando à construção de credibilidade de um líder ou agremiação partidária ou no estímulo de apoio de um sistema político, com regime participativo ou ditatorial.

\footnotetext{
A comunicação política não pode ser entendida somente como um conjunto de mensagens que ocorrem dentro de um sistema político. Ela permite atividade de formação de demandas, de mudanças nas próprias respostas do sistema, de compreensão dos processos políticos, ou, ainda, como unidade de análise das teorias políticas, da sociolinguística, da sociologia de massas e dos estudos de concentração e distribuição do poder político dentro dos diversos grupos organizados. (SANTOS, 2007, p.65).
}

Governos e atores políticos nem sempre consideram as ações analíticas da comunicação política como estratégia de construção de imagem. Tal situação se dá pelo fato 
da carência de profissionais realmente preparados para o desenvolvimento correto e funcional de ações comunicacionais voltadas ao poder público.

No ambiente público, as equipes que normalmente formam e articulam as estratégias de comunicação política, nem sempre são preparadas para tal feito. São normalmente profissionais de comunicação que nunca atuaram no poder público, porém, por fatores de indicação de cargos e proximidades partidárias acabam exercendo funções de comunicação e assessoria do político.

A ausência de profissionalismo pode reportar em vários problemas para a imagem pública, principalmente quando existe a necessidade de articulação com as mídias regionais e nacionais. Fatos mal explicados e conduzidos podem reportar más interpretações por parte da mídia, que, a cada ano que passa torna-se mais interativa e convergente.

O maior problema nesse cenário contemporâneo é a grande e exacerbada quantidade e velocidade da informação, que leva o eleitor cidadão a ler uma determinada notícia negativa, mas devido à quantidade de outras informações, acaba formando a imagem daquele ator político de acordo com o que leu superficialmente e não se manifesta em aprofundar-se nas acusações e compreensão do cenário.

Segundo Macedo (2007, p. 89) "com a ampliação dos sistemas de comunicação e telecomunicação, os canais de comunicação ampliarão o seu leque de abrangência na transmissão de informação, e com esse crescimento, o poder privado e poder público vislumbraram essa perspectiva de crescimento na comunicação com seus pares”.

Com o avanço do voto eletrônico e das telecomunicações, o eleitor tem desenvolvido cada vez mais o seu senso argumentativo e reflexivo dos candidatos a cargos eletivos. Seu processo decisório na escolha dos postulantes aos cargos eletivos está cada vez mais relacionado a informações que possam circular pelos meios de comunicação impressos e eletrônicos. Por esse motivo, a preocupação de um bom relacionamento com os canais midiáticos é fator estratégico para o fortalecimento e proteção de uma imagem pública de um ator político.

\subsection{Evoluçoes nos sistemas eleitorais}

O Brasil desde o seu descobrimento passou por inúmeras alterações em seu processo eleitoral, influenciado por segmentos da sociedade em busca de poder e monopólio de recursos financeiros e terras. Um problema apresentado historicamente foi o processo de transparência na escolha de representações políticas que perdura em debates na sociedade brasileira até os dias atuais. 
Com predominância portuguesa, o Brasil, diferente de seus países limítrofes, cuja influência colonizadora foi balizada pela ordem espanhola, recebeu por séculos, características lusitanas no comportamento de seu povo, das tradições culturais à influência de seleção de seus representantes políticos.

Mesmo depois da Proclamação da República, em 1889, o voto ainda não era direito de todos. Menores de 21 anos, mulheres, analfabetos, mendigos, soldados rasos, indígenas e integrantes do clero estavam impedidos de votar.

O fenômeno da burla em sistemas eleitorais é um problema enfrentado em diversas nações, relatados em seus anais eleitorais, bem como na história eleitoral brasileira.

A disputa pelo poder político em uma determinada região ou nação é tratada por muitos grupos de interesse como vital para as suas articulações comerciais e financeiras, por consequência, visando o sucesso no pleito eleitoral, a opção pela fraude é escolhida, com vistas manter a todo custo o domínio na população envolvida e vigente.

No período do Estado Novo, institucionalizado por Getúlio Vargas no ano de 1937, o ambiente de eleições diretas foi sucumbido, ações nos bastidores político nacional foram articuladas para a tomada do poder federal, limitando o processo eleitoral até então dominado nas últimas décadas pelos estados de São Paulo e Minas Gerais, período denominado "República do café com leite".

Na visão de Duverger (1984, p.36)

A escolha de um sistema eleitoral é consequentemente determinada por fatores concretos, depende, sobretudo, da função que os representantes eleitos devem exercer. Se o objetivo é formar um governo forte e estável, capaz de tomar decisões no decorrer de toda a legislatura, o sistema de pluralidade é o melhor método. Se o objetivo é formar uma assembleia consultiva que expresse todas as nuanças de um país, a representação proporcional é claramente preferível.

Após o regime do Estado Novo, o Brasil vivenciou um período de estruturação democrática, que sobreviveu até o golpe militar de 1964. A conquista das mulheres é um dos pontos fortes a ser enaltecido nesse período, principalmente com relação à participação eleitoral, seja como eleitora ou candidata a cargos proporcionais. Na visão de Avelar (1989, p. 16)

Há claros sinais de que as mulheres adquiriram novos papéis econômicos e políticos, e, de algum modo, tentam redefinir suas relações, tanto no interior da família quanto na sociedade. Seus esforços nesse sentido ampliaram-se, chegando até os valores culturais, como é possível depreender dos debates em torno de questões como divórcio, aborto, independência. [...] Parece-nos importante reafirmar e introduzir como elemento essencial na análise o fato de que essa desvinculação das mulheres brasileiras do universo tradicional consolidou uma nova realidade objetiva para grande parte delas. Daí decorre 
a explicação dos padrões ou tendências do voto e das orientações políticas da mulher deve ser buscada no contexto dos papéis em que se expressa a tensão produzida por essa mudança.

A atuação militar no Brasil (1964-1985) foi caracterizada por manifestações desenvolvimentistas, com claro objetivo patriótico, inerente do comportamento militar. Duas correntes analíticas descrever esse período: o posicionamento favorável explana acerca dos fatores positivos do desenvolvimento estatal nacional, com aumento dos índices econômicos e posicionamento do Brasil perante nações em franca ampliação econômica nos idos dos anos 70.

Após esse período até a presente data, o modelo democrático de direito está em vigor, com liberdade de expressão pelos órgãos de fomento informacional e abertura para participação da sociedade civil no processo eletivo de representantes proporcionais e majoritários.

O sistema político brasileiro vigente permite a integração dos diversos atores da sociedade em prol de debates temáticos nos processos decisórios nacionais. Além de propiciar uma atividade conjunta com o poder privado nas ações público-privadas relacionadas à captação de recursos e desenvolvimento de projetos com caráter desenvolvimentista.

Em uma análise do sistema eleitoral norte-americano alguns pontos são diferenciados do modelo brasileiro. O presidente não é eleito pelo voto direto, mas por uma instituição chamada colégio eleitoral, pois de acordo com a Constituição Americana, a escolha do presidente e seu vice dependem de delegados estaduais, estes sim escolhidos pelos eleitores. Essa dinâmica eleitoral se deve a continuidade das regras eleitorais a décadas, devido à longa trajetória democrática dos EUA.

Nessa estrutura, cada um dos 50 estados tem direito a um número de delegados proporcional ao total de representantes que possui no Congresso Nacional, sendo um para cada deputado e um para cada dois senadores. Isto faz com que o tamanho e o número de estados em que cada candidato venceu tenham muito mais peso no resultado final da eleição do que o número de votos total feitos por cada um.

A disputa nesse sentido deve ser muito mais planejada do que em uma análise de macro regiões, visto que a disputa é direta em cada estado de representatividade e as pesquisas de intenção de votos devem ser controladas de maneira específica, visto a relevância de conquista de vitórias nos estados da federação norte-americana.

O Colégio Eleitoral possui 538 membros ao todo, que possuem poder de decisão superior a milhões de votantes. Para eleger-se presidente, o candidato precisa obter os votos de 270 desses membros. Todavia, em 48 dos 50 estados, se um candidato obtém maioria de votos, ele recebe todos os respectivos votos eleitorais daquele estado. (SMITH, 2008, p.18). 
A não obrigatoriedade do voto é uma característica do sistema eleitoral norteamericano que difere completamente do modelo brasileiro, no qual é obrigatório o voto ao eleitor préviamente cadastrado, considerado uma das ações cidadãs obrigatórias de serem realizadas, ou ao menos justificadas.

O financiamento de campanha nos EUA pode ser realizado de duas formas, público ou com recursos privados, escolhidos previamente pelos candidatos em véspera de campanha. No Brasil o financiamento de campanha está condicionado aos partidos políticos que recebem percentualmente o fundo partidário e podem repassar aos seus candidatos, como também financiamento privado de campanha.

Nesse sentido, nas eleições presidenciais de 2008, o candidato Democrata Barack Obama, atual presidente eleito optou pela captação de recursos privados de campanha, visto a pespectiva de conseguir angariar mais fundos do que a escolha limitada de gastos públicos, mesmo tendo informado préviamente sua pré-disposição a financiamento público.

O dinamismo eleitoral, seja nos EUA ou Brasil conduzem uma alta exigência aos profissionais de Comunicação Política, consultores e demais analistas, devido a alta velocidade de ajustes e adequações nas relações de propaganda e contrapropaganda nas situações eleitorais e pós-eleitorais, envolvidas com o margeamento de imagem governamental em conjunto.

\subsection{Panorama da Consultoria Política no Brasil e nos Estados Unidos}

Apesar das diferenças relacionadas ao modelo eleitoral serem acentuadas, a atuação dos consultores políticos nos dois países possuem diversas características semelhantes, principalmente no sentido organizacional dos planejamentos de comunicação e gestão de imagem, quanto a construção de um ator político preparado para interação com a mídia.

Brasil e EUA possuem ampla liberdade de imprensa, fator considerado positivo que propicia um maior dinamismo e transparência no trato com o universo político. $\mathrm{Na}$ visão da comunicação política, essa facilidade da mídia em acompanham as ações de uma personalidade pública ligada a político exige maior perspicácia e competência no desempenho de ações eleitorais e pós-eleitorais.

Uma situação que explicita a organização eleitoral de um país é o conjunto de órgãos reguladores do poder público e de grande parte dos profissionais ligados a prestarem serviços a estrutura pública. Associações que envolvem profissionais de comunicação e marketing 
político são relevantes no sentido de promover um filtro de qualidade no conceito de consultoria para os envolvidos no ambiente público.

Um profissional norte-americano relacionado ao ambiente de consultoria é Joseph Napolitan, sócio da Joseph Napolitan Associates Inc, sede nos Estados Unidos, presta serviços de consultoria política, incluindo pesquisas de opinião, consultoria de mídia, pesquisa e análise, desenvolvimento e estratégia política. Trabalhou como consultor geral em mais de 100 campanhas políticas nos Estados Unidos e muitos outros em todo o mundo.

Foi fundador e primeiro presidente da Associação Americana de Consultores Políticos e também co-fundador da IAPC (Associação Internacional de Consultores Políticos) junto com o Francês Michel Bongrand em novembro de 1968. Juntos convidaram alguns veteranos responsáveis pelas campanhas políticas de quinze países e se reuniram em Paris onde trocaram informações e opiniões sobre a profissão emergente de consultoria política. No final desse encontro, eles decidiram formalizar seus interesses profissionais, organizando a Associação Internacional de Consultores Políticos (IAPC).

Atualmente é representada por aproximadamente 180 homens e mulheres como membros ativos, constituindo uma ampla atividade profissional política.

Conforme Figueiredo (2002, p.122), destaca "Joseph Napolitan, e os demais assessores políticos dos Estados Unidos não se limitam apenas ao marketing eleitoral, mas, ampliam a assessoria tais como o aconselhamento de pessoas, dirigentes e empresários a como reagir diante de realidade política econômica e social mais ampla".

O IAPC realiza uma reunião anual para trocar opiniões e informações sobre políticos, desenvolvimentos e técnicas de campanha organizacional. Esta conferência acontece em Novembro de cada ano e em uma cidade diferente.

No Brasil a estrutura organizacional de uma Associação existe e apresenta características semelhantes, intitulada Associação Brasileira dos Consultores Políticos - ABCOP é atualmente uma representação ativa dos profissionais que estão em constante interação com o ambiente político eleitoral brasileiro. Fundado em 1991, conta com profissionais associados em todo território nacional e promove cursos de formação relacionados à comunicação política.

Presidida pelo consultor Carlos Manhanelli, a ABCOP fundamenta caminhos para o aumento do profissionalismo brasileiro, apesar de poucas décadas desde a redemocratização nacional, diferente da maturidade norte-americana, cujo período democrático e eleitoral é mais maduro e estruturado.

Segundo ABCOP (2010) a associação terá por objetivo:

assistir e representar os profissionais e empresas associados em todos os seus interesses comuns, a fim de lhes possibilitar maior e melhor desenvolvimento, proteção e valorização técnica dos seus serviços, além de promover maior convívio entre eles; estabelecer relações com Sindicatos e 
Federações, bem como entidades oficiais e particulares que possam vir a colaborar com a Associação para a consecução de seus fins; colaborar com os órgãos do governo na elaboração, implantação, execução e controle de programas relacionados com o desenvolvimento do país e nos quais os profissionais e empresas associados possam oferecer qualquer subsídio e atuar como órgão técnico e consultivo, junto a entidades oficiais e particulares quando necessário, no estudo e solução de problemas que se relacionem com os serviços representados.

Como complemento da pesquisa, é salutar apresentar o papel da comunidade científica com relação à promoção de cursos relacionados à Comunicação Política. No Brasil várias comunidades e Universidade promovem debates a respeito e existem homologadas duas Associações de pesquisa: a primeira é a Sociedade Brasileira de profissionais e pesquisadores em Comunicação e Marketing Político - POLITICOM, que reúne pesquisadores de diversos estados da federação brasileira em grupos de pesquisa e nos encontros anuais intitulado como Congresso Brasileiro de Marketing Político, atualmente na nova edição.

A Associação Brasileira dos Pesquisadores em Comunicação Política COMPOLITICA também organiza encontros bienais para a discussão de projetos de pesquisa direcionados a área. Ambas promovem cursos e debates durante todo o ano, em diversas Universidades nacionais e internacionais.

Uma instituição de ensino brasileira de referência internacional em Gestão Pública é a Fundação Getúlio Vargas, com oferta de cursos de graduação, especialização Lato Sensu e Stricto Sensu na linha de pesquisa Administração Pública.

Em universo norte-americano foi realizada pesquisa eletrônica com a palavra-chave "the graduate school of political management" (A pós-graduação de gestão política). De um total de 29.900, os 10 primeiros itens na ocorrência da pesquisa, todos eles remetem a página ou sobre a Universidade George Washington, escola de gestão pública.

De acordo com o sítio da Universidade George Washington (GW) é uma universidade privada, mista, não-sectária localizada em Washington, DC Fundada em 1821 como o Colégio colombiano em terreno cedido pelo ex-presidente George Washington, a Universidade, desde então, desenvolveu-se e tornou-se uma importante instituição de ensino e pesquisa. Atualmente conta com 4500 funcionários e mantêm aproximadamente 11.000 alunos de graduação ao ano e outros 12.500 alunos de pós-graduação ao ano.

Foi também desenvolvida uma visita a sítios americanos com o tema "of undergraduate school of political management" ou escolas de graduação em gestão pública. O resultado obtido foi de 5.110 .000 e seguindo nosso critério de analise e evidenciação dos 10 primeiros itens de ocorrência verificamos que para esta pesquisa não foi possível utilizar 
aspas, desta maneira, amplia-se os resultados obtidos, razão pelo grande volume no resultado obtido.

Os dados evidenciaram que quando o assunto sobre graduação e pós-graduação em gestão política a ser pesquisada nos Estados Unidos a mais importante fonte de informação para os americanos é a Universidade George Washington e em ambiente brasileiro a Fundação Getúlio Vargas, localizada presencialmente nos estados de São Paulo e Rio de Janeiro, apesar de promover formações com plataforma a distância para todo o país.

Com relação à internet, uma pesquisa no sítio Google Americano sobre o tema "Political consultants" ou consultores políticos resultou, em 26 de maio de 2010, em 265.000 páginas. Para análise e evidenciação foram utilizados os 10 primeiros itens na ocorrência de pesquisa.

É importante informar que o serviço do sítio Google classifica os itens pelos mais acessados. Desta forma, foi possível realizar uma pesquisa de caráter qualitativo, pois a incidência de acessos se relaciona com a aceitação dos respectivos conteúdos. Com estas informações, evidenciou-se que a página mais acessada é a da American Association of Political Consultants - AAPC (Associação Americana de Consultores Políticos), com sede em Washington, desta maneira é a principal fonte de consulta de pessoas interessadas sobre o assunto.

Em pesquisa eletrônica final, o tema de busca foi "Political Marketing" ou Marketing Político. De um total de 46.900, o primeiro item refere-se a um sitio de mídia política, vinculado ao espaço patrocinado do Google, na ferramenta Adwords.

O segundo item refere-se a um sitio sobre livros de marketing político, sendo apresentado como o primeiro livro abrangente de se concentrar em marketing político, focado a alunos, bem como candidatos, partidos, políticos eleitos e governos ao redor do mundo; podendo utilizar conceitos de marketing e ferramentas para ganhar eleições e permanecer no cargo.

\section{CONSIDERAÇÕES}

Diante do contexto apresentado dos dois países é possível verificar o aumento do grau de profissionalismo exigido em toda a rede de envolvidos para a sustentação do poder público. A competitividade e a convivência estratégica com as mídias integradas são desafios significativos para qualquer ator político.

Brasil e EUA apresentam diferenças quanto a sua forma de executar e desenvolver suas condicionantes eleitorais, principalmente no sentido de votação presidencial, no quesito 
de voto direto e colegiado de votação, com delegados, porém os mecanismos de condução de uma campanha eleitoral são semelhantes no sentido de planejamento de comunicação e marketing político, visto a semelhança com relação à dimensão territorial e populacional.

Por apresentar um histórico mais antigo com relação ao ambiente democrático, os EUA conduzem com maior conservadorismo seu sistema eleitoral, no qual várias diretrizes estruturais são mantidas há décadas, principalmente as relacionadas na integração e execução dos poderes.

O Brasil ainda vive um período recente de redemocratização, apesar de três décadas passadas desde o fim do regime militar, ainda é possível verificar ausência e limitações na Constituição vigente, bem como nas premissas relacionadas aos poderes públicos e políticos.

Outro fator que inibe o comportamento eleitoral com maior maturidade e reflexão são as problemáticas consequentes da má estrutura educacional nacional, que possui impactos diretos na participação ativa da população com o ambiente público, fatores com baixos níveis de inclusão digital e instrução reportam a uma dificuldade na condução de um regime democrático mais puro, visto participação popular.

Nesse parâmetro, as ações midiáticas de comunicação política nos dois países utilizam com grande competência os recursos de condução de massa, difusão de propaganda ideológica e fomento de técnicas de marketing político, nesse sentido, os EUA utilizam mais a Internet para envolvimento da população, em contrapartida, o sistema brasileiro é mais avançado no quesito de votação eletrônica, tanto na logística de votação nos pleitos eleitorais, como nas apurações de resultados das eleições.

Ambos os países possuem Associações que estimulam a formação e buscam garantir a profissionalização dos envolvidos na comunicação política, principalmente com relação ao planejamento de campanhas e estratégias pré, eleitorais e pós-eleitorais.

As Universidades também estimulam a formação para o poder público e comunicação pública, porém em grau limitado pela dimensão dos dois países. Associações como ABCOP no Brasil, IAPC e AAPC em caráter norte-americano e internacional corroboram para a condução de equipes mais competentes e eficazes no trato da comunicação política.

Associações de pesquisa também contribuem de modo relevante e estimulam o cenário acadêmico científico na promoção de cursos e debates com a temática política, democracia, sociedade e comunicação. Tendenciosamente, a evolução tecnológica permitirá maior acesso informacional a população, favorecendo sua reflexão com relação ao comportamento do universo político, exigindo por consequência maior competência nos poderes e melhores e mais preparados representantes no sistema público. 


\section{REFERÊNCIAS}

ABCOP. Ata da assembléia de constituição da Associação Brasileira dos Consultores

Políticos e Assessores Eleitorais. Disponível em < http://www.abcop.com.br/a/index>. Acesso em 04.jul.2010.

ALVA DE LA SELVA. A. Hacia la sociedad de la información y el conocimiento.

Perpectivas y prospectivas de los medios de comunicación. Cidade del México: UAM, 2006. ARAÚJO, Cícero Reimão Resende de. Estado moderno, democracia e comunicação. In KUNSCH, Margarida Maria Krohling. Gestão Estratégica em Comunicação

Organizacional e Relações Públicas. São Caetano do Sul: Difusão, 2008.

AVELAR, Lúcia. O segundo eleitorado: tendências do voto feminino no Brasil. Campinas: UNICAMP, 1989.

BRANDÃO, Elizabeth. Conceito de comunicação pública. In: DUARTE, J (Org.).

Comunicação Pública: estado, mercado, sociedade e interesse público. São Paulo: Atlas, 2007.

DUVERGER, Maurice. Participação político-social - 1988: Brasil e Grandes regiões. Rio de Janeiro: FIBGE, 1990.

FIGUEIREDO, Ney Lima. Jogando para Ganhar - Marketing Político, verdade e mito. $2^{\mathrm{a}}$ Ed. São Paulo: Geração Editorial, 2002.

HASWANI, Mariângela. Comunicação Pública e Política. In: KUNSCH, Margarida Maria Krohling (Org.). Gestão Estratégica em Comunicação Organizacional e Relações

Públicas. São Caetano do Sul: Difusão, 2008.

MACEDO, Roberto Gondo. A importância da assessoria de imprensa no Marketing Político. In: QUEIROZ, Adolpho; MANHANELLI, Carlos; BAREL, Moises (Org.). Marketing

Político: do comício a Internet. São Paulo: ABCOP, 2007.

IAPC. Disponível em: < http://www.iapc.org/>. Acesso em 23.maio.2010.

SANTOS, Célia Retz dos. Opinião Pública \& Marketing Político. Bauru: Editora FAAC, 2007.

SMITH, Eduard. Power and politics. New York: IAA/CFF, 2008.

SORJ, Bernardo. Internet, espaço público e marketing político - Entre a promoção da comunicação e o solipsismo moralista. Disponível em

$<$ http://www.scielo.br/scielo.php?pid=S0>. Acesso em 30.maio.2010. 
GWU. The George Washington University. Disponível em

$<$ http://www.gspmonline.com/gwu/about_gw.asp $>$. Acesso em 25.maio.2010.

Original recebido em: 30/10/2012

Aceito para publicação em: 28/11/2014

Sobre os autores

PAULO CEZAR ROSA

Doutor em Comunicação Social, Docente da Universidade Metodista de São Paulo e Consultor na área de gestão e comunicação.

ROBERTO GONDO MACEDO

Pós-doutor em Comunicação Política pela ECA/USP. Doutor em Comunicação Social. Docente e Pesquisador na Universidade Presbiteriana Mackenzie. Presidente da Sociedade Brasileira de Pesquisadores e Profissionais de Comunicação e Marketing Político POLITICOM. 